\title{
O “AMERICANISMO" E A CRIAÇÃO DA CADEIRA DE ESPANHOL NO ENSINO SECUNDÁRIO BRASILEIRO (1917-1926)
}

DOI: http://dx.doi.org/10.1590/2236-3459/57416

\author{
Anselmo Guimarães \\ Universidade Federal de Sergipe, Brasil. \\ Josefa Eliana Souza \\ Universidade Federal de Sergipe, Brasil.
}

$\cos 80$

\begin{abstract}
Resumo
Este artigo investigou as contribuições do "Americanismo" para a criação da cadeira de espanhol no ensino secundário brasileiro, as finalidades imediatas da institucionalização do espanhol como disciplina escolar e as dificuldades desse processo no Brasil, de 1917 a 1926. O estudo fundamentou-se nos pressupostos teórico-metodológicos da história cultural e, sobretudo, da história das disciplinas escolares no diálogo com André Chervel (1990). A análise evidenciou que apesar da introdução do ensino da língua espanhola como troca de gentileza ao ato do Governo do Uruguai, não agregou ao ensino qualquer outro objetivo.

Palavras-chave: americanismo, cadeira de espanhol, ensino secundário.
\end{abstract}

\section{"AMERICANISM" AND THE CREATION OF THE SPANISH SUBJECT IN THE BRAZILIAN SECONDARY EDUCATION (1917-1926)}

\begin{abstract}
This article has investigated the contributions of "Americanism" to the creation of the Spanish Language subject in the Brazilian secondary education, the immediate aims of the institutionalization of Spanish as a school subject and the difficulties of such process in Brazil from 1917 to 1926. The study has been based on the theoretical-methodological assumptions of cultural history and especially on the history of school subjects in the dialogue with André Chervel (1990). The analysis has evidenced that despite the introduction of the Spanish Language teaching as an exchange of kindness with the Government of Uruguay that has not aggregated any other aim to the teaching process.

Keywords: americanism, spanish language subject, secondary education.
\end{abstract}

\section{EL “AMERICANISMO” Y LA CREACIÓN DE LA CÁTEDRA DE ESPAÑOL EN LA ENSEÑANZA SECUNDARIA BRASILEÑA (1917-1926)}

\section{Resumen}

Este artículo investigó las contribuciones del "Americanismo" a la creación de la cátedra de español en la 
educación secundaria de Brasil, las finalidades inmediatas de la institucionalización del español como disciplina escolar y las dificultades de este proceso en Brasil, a partir de 1917 a 1926 . El estudio se basó en los principios teóricos y metodológicos de la historia cultural y sobre todo de la historia de las disciplinas escolares en diálogo con André Chervel (1990). El análisis mostró que a pesar de la introducción de la enseñanza de la lengua española como intercambio de gentileza al acto del Gobierno de Uruguay, no se añadió a la enseñanza cualquier otro propósito.

Palabras clave: americanismo, cátedra de español, enseñanza secundaria.

\section{LE “AMÉRICANISME” ET LA CRÉATION DE LA CHAIRE D’ESPAGNOL DANS L’ENSEIGNEMENT SECONDAIRE BRÉSILIEN (1917-1926)}

\section{Résumé}

Dans cet article nous avons mené une enquête sur les contributions de le "Américanisme" envers la création de la chaire d'espagnol dans l'enseignement secondaire brésilien, sur les objectifs immédiats de la institutionnalisation de l'espagnol en tant que discipline scolaire et sur les difficultés de ce processus au Brésil, de 1917 à 1926. L'étude a été basée sur les présupposés théoriques-méthodologiques de l'histoire culturelle et surtout, sur l'histoire des disciplines scolaires dans le dialogue avec André Chervel (1990). Cette analyse a mis en évidence que, malgré que l' introduction de l' enseignement de la langue espagnole ait été un échange de gentillesse pour l' acte du gouvernement de l'Uruguay, cela n' ajouta à l' enseignement aucun objectif particulier.

Mots-clés: américanisme, chaire d'espagnol, enseignement secondaire. 


\title{
Apresentação
}

$\mathrm{O}$

"Americanismo", ou seja, a aproximação ou cooperação entre os países do continente americano, esteve presente nos discursos brasileiros, no início da República, principalmente, no que se referia às relações internacionais entre Brasil, Estados Unidos e países sul-americanos. No início do século $\mathrm{XX}$, essas demonstrações de amizade entre os países foram decisivas para a criação da cadeira de espanhol no ensino secundário brasileiro, em 1919, institucionalizando uma nova disciplina com "finalidade" política e que em pouco tempo, por não ter uma "finalidade" aceita pela comunidade escolar, para usar a terminologia de Chervel (1990), foi rechaçada por esta comunidade como veremos adiante.

Desta forma, este trabalho tem como objetivo investigar as contribuições do "Americanismo" para a criação da cadeira de espanhol, as finalidades imediatas do governo para a institucionalização do espanhol como disciplina escolar, bem como as dificuldades desse processo no Brasil a partir de uma visão metodológica baseada nos pressupostos da história cultural e história das disciplinas escolares, no período cronológico de 1917 a 1926. O ano de 1917 diz respeito ao fato do Governo do Uruguai ter criado uma cadeira de português em seu ensino secundário e ter solicitado ao Brasil que, em reciprocidade, criasse a cadeira de espanhol. Ao passo que 1926 justifica-se por ser o último ano do ensino de espanhol, nesta primeira tentativa de inclusão da disciplina no ensino secundário brasileiro. O estudo foi estruturado no diálogo com Chervel (1990).

As relações amistosas entre o Brasil e os outros países americanos, principalmente na área da cultura e educação, somente passam a ter efetividade após o Brasil adotar a república como forma de governo. No Segundo Império não há registro de que o Imperador D. Pedro II tenha feito alguma viagem diplomática para os países vizinhos:

\begin{abstract}
[D. Pedro II] foi familiar aos poetas franceses, aos pintores florentinos, aos músicos de Milão, sendo conhecido e apontado nas ruas de Londres e nas praias elegantes da Europa, mas nunca se dignou em visitar Buenos Aires de Mitre e Montividéu [sic] de Flores, para só citar as cidades dos seus aliados na guerra contra Solano López. Ficou célebre sua viagem à Rússia, mas não consta que haja tido a intenção sequer de ir a Assunção, a La Paz, a Lima, Quito, Bogotá e Caracas, as capitais de países com paredes e meias. (GOYCOCHÊA apud WOGAN, 1948, p. 1)
\end{abstract}

Obviamente que essas relações internacionais com os seus vizinhos não passaram a existir, de uma hora para outra, apenas com a mudança da forma de governo. Essa mudança oficializou e impulsionou o que de modo lento já se encaminhava na sociedade. Uma publicação no Diário do Rio de Janeiro (1840) ressaltava a necessidade de o Brasil entrar na "grande família americana" e declarava: "Já nos conveio a monarchia sim, mas constitucional, representativa, e federal; para o diante em seu tempo adequado só nos convirá a republica, que é a natural tendência da américa!!!!!!! Verba volant scriptamanent" (DIÁRIO DO RIO DE JANEIRO, 1840, p. 2) ${ }^{1}$.

No campo do ensino de línguas, mesmo no Brasil Império, havia o interesse no aprendizado da língua espanhola, com professores particulares que se ofereciam para

\footnotetext{
1 Decidimos usar a grafia da época nas citações diretas, da mesma forma como estão nos documentos pesquisados.
} 
ensinar o idioma de Cervantes e escolas particulares com cursos a preços "módicos". Esta procura deveu-se ao fato de que chegavam ao Brasil livros provenientes da Espanha e países hispano-americanos, além de peças de teatro de companhias espanholas.

No final do século XIX, início da República, intensificaram-se as críticas aos programas de ensino que incluíam o italiano como idioma a ser estudado e deixavam de fora o espanhol. Em 1897, no projeto de reforma dos estabelecimentos de ensino do Exército constava aula da língua espanhola, mas o seu ensino não se efetivou no Decreto no. 2881, que aprovou o regulamento dos institutos militares de ensino, instituído em 1898.

Somente em 1905, com as demandas de uma maior integração com os países hispano-americanos nas áreas comercial e militar, a língua espanhola entrou efetivamente no currículo oficial das academias de comércio e do exército brasileiro. Na educação secundária o idioma passou a fazer parte do currículo oficial a partir de 1920, no Colégio Pedro II, fruto de gentilezas trocadas entre os governos do Uruguai e do Brasil, sem uma justificativa pedagógica para o seu ensino.

\section{Contribuições do "Americanismo" na criação da cadeira de espanhol no ensino secundário}

Com o início da República, a educação secundária refletia o clima de mudanças na formação de um novo cidadão, apesar de o novo regime ter fracassado na invenção de um mito de origem republicana (CARVALHO, 1990), mas com o burilamento de ideias as mais diversas sobre o papel do Estado, do cidadão, e as relações entre ambos. Houve muitas vezes aproximação da massa popular ao novo governo, bem como, em outros momentos, grandes embates e revoltas contra a nova ordem que estava se estabelecendo. No campo cultural, abriu-se o leque das opções com a aproximação aos países hispano-americanos.

A partir da segunda metade do século XIX, o Brasil mudou o foco de sua atenção mirando para os Estados Unidos da América. Muitos intelectuais, principalmente os liberais, perceberam a cultura e a pedagogia estadunidenses como um símbolo de renovação e progresso. Esse processo de direcionamento das atenções dos brasileiros para a cultura norte-americana se deveu muito à ação dos protestantes missionários que vieram para o país. Os protestantes, principalmente os Presbiterianos, difundiram no Brasil "a nova visão de mundo trazida pelas missões protestantes norte-americanas [que] estava impregnada pelos ideais liberais" (CHAMON, 2008, p. 51).

Essa mudança de paradigma cultural que o Brasil apresentou, afastando-se do raio da ação cultural da Europa, mormente da França, para vislumbrar na América novas possibilidades por conta da influência norte-americana, promoveu aproximação das políticas culturais dos países americanos no final do século XIX e início do XX. Um dos exemplos foi apresentado por Vieira (1980) quando tratou da presença de protestantes norte-americanos enviados para o Brasil pela Sociedade Bíblica Americana, como o pastor James Cooley Fletcher que, após vinte anos de esforços vãos para preencher o cargo de capelão do porto do Rio de Janeiro, a sociedade dos marítimos americanos enviou ao Brasil esse ministro presbiteriano, que havia se oferecido para a missão de servir os americanos aqui residentes. Fletcher se integrou na defesa da imigração, tendo participado da Sociedade Internacional de Imigração, além de ser um divulgador da 
reforma educacional efetuada por Horace Mann, em Massachussets (1837-1848). Esta reforma foi uma das referências utilizadas pelo deputado Tavares Bastos nos estudos que realizou sobre a educação brasileira (SOUZA, 2012).

No entanto, houve reações contrárias ao que foi chamado de "americanismo", principalmente pela aproximação do Brasil com os Estados Unidos. Essa posição antiamericanista pode ser entendida como uma herança do Brasil Império, que tinha uma administração política fortemente afrancesada em face da República, que começou a voltar-se para o modelo americano. Eduardo Prado (1860-1901), bacharel em direito, escritor e publicista, com fortes tendências monarquistas, escreveu em 1893 o livro $A$ illusão americana, com severas críticas contra o que chamou de "insanidade da absoluta confraternização que se pretende impôr entre o Brazil e a grande republica anglo-saxonia, de que nos achamos separados, não só pela indole e pela lingua como pela historia e pelas tradicções do nosso povo" (PRADO, 1917, p. 1).

Prado entendia que a fraternidade era uma mentira e em uma obra de 264 páginas expõe os motivos pelos quais a confraternização americana seria uma farsa. Segundo o autor, o Brasil não poderia argumentar que somente porque estando situados no mesmo continente, os países americanos teriam que ser fraternos e cita, para corroborar com isso, todas as desavenças e guerras entre os países das Américas ressaltando "eis ahi a fraternidade Americana. [...] nem o Brazil physico, nem o Brazil moral, formam um systema com aquellas nações" (PRADO, 1917, p. 5).

Em que pese $o$ fato de ter havido reações contrárias, o americanismo foi defendido por brasileiros ${ }^{2}$ que avalizaram o novo direcionamento político, cultural e ideológico do país, com "[...]foi significativa a influência de brasileiros, como Monteiro Lobato e Gilberto Amado, que escreveram livros, após viagens aos EUA, contando as maravilhas vistas e sentidas, apontando os novos paradigmas buscados" (CUNHA, 1980, p. 197).

Tavares Bastos ${ }^{3}$, mesmo antes da proclamação da República, já defendia que os hábitos da sociedade brasileira necessitavam de mudanças e que o contato com os Estados Unidos da América era uma possibilidade de conhecimento rumo à transformação dos costumes e hábitos "degenerados" do povo brasileiro. Segundo o parlamentar, o Brasil teria muito a ganhar com a aproximação com os norte-americanos, pois eram um povo com espírito liberal, com um grande crescimento moral e material, que defendia a entrada no país de imigrantes estrangeiros, principalmente de norteamericanos (SOUZA, 2012).

Essas iniciativas teriam contribuído para a nação brasileira também passasse a exercitar uma movimentação em prol de políticas culturais que lhe aproximasse dos países hispano-americanos, no final do século XIX e início do XX. Então a ideia era incentivar o estudo da língua espanhola, como o Brasil já o fazia com a língua dos norteamericanos. As relações políticas e comerciais com o Uruguai e outros países hispanofalantes, desde a proclamação da República, levaram o Brasil a ter um maior interesse

\footnotetext{
2 Entre os intelectuais que demonstraram simpatia pelo modelo de educação inspirado no referencial norteamericano é possível citar: Aureliano Cândido Tavares Bastos (1839-1875), Rui Barbosa de Oliveira (1849-1923), Oscar Thompson (1872-1935), Francisco Rangel Pestana (1839-1903), entre outros.

3 Aureliano Cândido Tavares Bastos foi bacharel e doutor em direito, com mandato de Deputado pela província de Alagoas (SOUZA, 2012).
} 
pela língua dos vizinhos. Vários intercâmbios se intensificaram no primeiro quartel do século XX, como a admissão de oficiais da marinha uruguaia para praticar na marinha do Brasil; admissão de alunos das repúblicas americanas nas escolas militar e naval; admissão de alunos brasileiros nas escolas de Montevidéu; ingressos de estudantes da Argentina, Uruguai e Chile nos Institutos Superiores do Brasil (BRASIL, 1920). Todas essas iniciativas entre os países, principalmente sul-americanos, foram necessárias para manter uma integração, principalmente após a explosão da Primeira Guerra Mundial e a entrada do Brasil nesse conflito apoiando os Estados Unidos.

\section{Criação da cadeira de espanhol como gentileza governamental}

Os jornais, a exemplo do $A$ Época, divulgaram a decisão do ministro do Interior de criar no Colégio Pedro II uma cadeira de espanhol, em reciprocidade à idêntica proposta do Uruguai, de criar uma cadeira de português em seu ensino secundário. Essas relações entre os países de solicitações e convênios para o ensino das línguas vivas não eram incomuns. A Itália e a Argentina tinham um acordo, em 1907, de reciprocidade no ensino do italiano e do espanhol em seus países:

\footnotetext{
Vae ser creada uma cadeira de hespanhol no Pedro II

O dr. Carlos Maximillano, ministro do Interior, dirigiu ao director do Collegio Pedro Il o seguinte aviso:

"Havendo o governo da Republica Oriental do Uruguay creado uma cadeira de portuguez em um dos seus estabelecimentos officiaess, conforme a este ministerio communicou o das Relações Exteriores, declaro-vos para os devidos fins, que, nos termos do artigo 70, letra d, do decreto n. 11.530, de 18 de março de 1915 , se devia crear nesse estabelecimento uma cadeira de frequencia facultativa, de lingua hespanhola, e litteratura hispano-americana, como homenagem do Brazil ás demais nações, que neste continente falam esse idioma e como meio de facilitar e desenvolver o intercambio intellectual entre o nosso paiz e os povos hispano-americanos." (Jornal A Época, 1917, p. 5)
}

No caso brasileiro, por que justamente no colégio mantido pelo governo federal? Entendemos que a intenção era que, como o estabelecimento era modelo para as demais instituições de ensino secundário no país, a língua espanhola poderia ser levada para todos os estados brasileiros sem a necessidade de se criar uma legislação nova ou mesmo alteração do Decreto 11.530, de 15 de março de 1915, que regulamentava o ensino secundário e superior do país, o que, como veremos adiante, não aconteceu.

É necessário compreender que o Colégio Pedro II, criado em 1837, era uma instituição modelo, sendo seguida por outras em todo país, tanto em relação ao currículo como também aos livros adotados e programas de ensino, haja vista a descentralização da educação promovida pelo Ato Adicional de 1834. A Lei no 16, de 12 de agosto de 1834, que promulgou o Ato Adicional, ou seja, que inseriu alterações adicionais na Constituição Federal de 1824, autorizava às Assembleias Legislativas Provinciais a legislar sobre a educação pública e estabelecimentos com aquela finalidade, exceto para Faculdades de Medicina, Cursos Jurídicos e Academias, ou seja, estabelecimentos de nível superior, iniciando com isso uma discussão nacional sobre a quem caberia organizar a instrução pública nacional.

Para minimizar essa descentralização e homogeneizar a educação secundária, 
pois nos anos seguintes surgiram "[...] os primeiros liceus provinciais ${ }^{4}$, localizados nas suas respectivas capitais: O Ateneu, do Rio Grande do Norte em 1835; os Liceus da Bahia e da Paraíba, ambos em 1836" (ROCHA, 1994, p. 59), o Governo Federal decidiu criar o Colégio Pedro II, um estabelecimento federal que pudesse servir de referência e que tivesse de alguma forma benefícios exclusivos para os seus formandos com o intuito de que os outros estabelecimentos se interessassem para nele se espelhar. Em 1843, por meio do Decreto n 296, de 30 de setembro, os bacharéis formados pelo Colégio Pedro II foram isentos de prestar exames de matérias preparatórias para ingressar em qualquer das Academias do Império. Posteriormente, os estabelecimentos equiparados ao estabelecimento federal também ganhariam os mesmos benefícios.

Desde a reforma instituída em 1915 pelo Decreto $11.530^{5}$, os certificados de conclusão de estudos de outras instituições só teriam efeitos legais, inclusive para que os alunos pudessem ingressar no ensino superior, se os respectivos estabelecimentos fossem equiparados ao Colégio Pedro II e inspecionados pelo Conselho Superior de Ensino. O Programa de Ensino instituído pela legislação era uma meta a ser alcançada, tanto pelos já equiparados quanto por aqueles que assim o desejavam, haja vista que significaria um status mais elevado e um diferencial em relação aos concorrentes e, em consequência, uma maneira de atrair mais estudantes. Os estabelecimentos de ensino secundário nem sempre seguiram à risca os seus currículos ${ }^{6}$, mas era um objetivo a ser alcançado, pois essa equiparação era importante e quando conseguida muito festejada, como no caso do Atheneu Sergipense, que conseguiu sua equiparação em 1908, promulgada pelo Decreto $\mathrm{n}^{-}$7.192, de 26 de novembro, recebida pela sociedade sergipana com muita euforia, como demonstra a notícia divulgada no jornal Folha de Sergipe, de 3 de dezembro de 1908:

Está equiparado ao Gymnasio Nacional o Atheneu Sergipense.

É esse um facto que deve encher de verdadeiro contentamento aos que amam sinceramente Sergipe.

Porque a instrucção é o maior propulsor do Progresso, sem o qual a Patria é nulla e mesquinha.

O acto do honrado titular da pasta do Interior, approvado os estatutos do nosso instituto de ensino secundario, veio preencher uma justa e indiscutível aspiração.

De facto, que maior serviço poderia ter sido prestado áquelles dos nossos patricios que, a mingua de recursos pecuniarios, não podem sahir para colher em terra estranha o fructo apetecido do saber?

Muita intelligencia, cujas locubrações seriam de reaes proveitos á sociedade, ficariam por ahi estioladas em detrimento do nosso progresso moral e, porque não dizel-o tambem material.

O que são as industrias, as artes, o commercio, senão manifestações da cultura humana?

Não ha felicidade possivel sem uma bem ministrada instrucção.

Bem comprehendendo isto, foi que a mocidade estudiosa da nossa terra recebeu com alvorotado entusiasmo a noticia da equiparação do Atheneu ao Gymnasio Nacional.

${ }^{4}$ Conforme Ferronato (2012, p. 88), na província de Pernambuco o liceu foi criado em 1825. Após 1834 deu-se a disseminação dos liceus pelo país.

${ }^{5} \mathrm{O}$ ministro Carlos Maximiliano assinou o Decreto no 11.530, em 18 de março, com o intuito de reformular o ensino, "elaborando um novo regime interno para o Colégio Pedro II e regulamentado o exame vestibular" (OLIVEIRA, 1999, p. 66-67).

6 Pesquisas atuais demonstram que os Colégios tinham um currículo diferente do adotado pelo Colégio de Pedro II. No caso de Sergipe sugerimos a leitura do trabalho da Profa. Dra. Eva Maria Siqueira Alves referente ao Colégio Atheneu Sergipense (2005). 
Em vistosa marche au flambeaux e precedidos da banda musical do Corpo de Policia, percorreram os estudantes diversas ruas da capital, indo ao Palacio do Governo, manifestar ao Presidente do Estado, o exm. sr. dr. Rodrigues Doria, que os recebeu carinhosamente no salão nobre, seus sinceros agradecimentos pela realisação de tão util melhoramento.

Interpretou os sentimentos da mocidade o velho professor, distincto lente do Atheneu, Manoel de Oliveira, que n'um feliz improviso saudou s. ex. pela brilhante conquista que acabava de obter, dotando a mocidade estudiosa de Sergipe de tão imprescendivel beneficio.

Por nossa vez, felicitamos ao eminente Presidente do Estado, dr. Rodrigues Doria. (FOLHA DE SERGIPE, 1908)

Uma vez equiparado o estabelecimento de ensino teria os mesmos benefícios que o estabelecimento federal e poderia conceder o mesmo grau. $O$ mais importante seria que os exames feitos nesses estabelecimentos teriam validade para a matrícula do aluno nos institutos federais de ensino superior. Dessa forma, o estabelecimento poderia conceder diploma de Bacharel em Letras e os seus exames seriam usados para admissão aos cursos superiores, não necessitando o alunado de se deslocar para outros estados. Na mesma década, é possível informar que, além do Atheneu Sergipense, mais trinta e sete estabelecimentos receberam a equiparação ao Colégio Pedro II, demonstrando a sua importância.

Após mais de um ano de espera, desde o anúncio feito pelo Ministro Maximiliano, por fim, em 1919, a inclusão do ensino da língua espanhola na educação secundária brasileira tem início com a abertura de concurso para a cadeira de espanhol no Colégio Pedro II, em decorrência do aumento de subvenção para a criação da disciplina, aprovado pela Lei no 3.674, de 07 de janeiro daquele ano. Dois meses após a aprovação da referida Lei, o Colégio Pedro II abriu concurso para uma cadeira de espanhol, e em 5 de abril o programa de ensino foi autorizado. Antenor de Veras Nascentes (1886-1972) foi aprovado no concurso, sendo nomeado em 18 de outubro de 1919. Em 1920, Nascentes publicou o compêndio Grammatica da Lingua Espanhola, pela Livraria Drummond Editora: primeira gramática de espanhol publicada no Brasil:

No processo de configuração da língua espanhola como disciplina escolar, o programa de ensino da cadeira de espanhol foi preparado por uma comissão composta pelos professores Gastão Ruch, Honorio de Souza Silvestre e Silva Ramos ${ }^{7}$, os quais completaram seu trabalho em 05 de abril de 1919. A Congregação do Colégio aprovou o programa em 10 de julho do mesmo ano. Os estudos da gramática foram privilegiados, pois, estavam baseados na tradição da gramatização latina ${ }^{8}$. Este foi o Programa de ensino da cadeira de espanhol aprovado em 10 de julho de 1919:

\footnotetext{
$1^{0}$ - Noções preliminares attinentes á grammatica castelhana, suas divisões e objectivos.

$2^{0}$ - Sons fundamentaes do hespanhol. Vogaes e consoantes, accentuação e quantidade.

$3^{\circ}$ - Morphologia e taxionomia do substantivo.

$4^{\circ}$ - Morphologia e taxionomia dos adjetivos.

5ํ- Estudos dos gráos.
}

\footnotetext{
7 Gastão Mathias Ruch Sturzenecker era professor de francês, Honorio de Souza Silvestre, professor de Geografia e José Júlio da Silva Ramos, professor de português, do Colégio de Pedro II.

${ }^{8}$ Por gramatização deve-se entender o processo que conduz a descrever e a instrumentar uma língua na base de duas teconologias, que são ainda hoje os pilares de nosso saber metalingüístico: a gramática e o dicionário (AUROUX, 1992).
} 
60 - Morphologia e taxionomia do artigo e do pronome.

7ํ - Da conjugação. Estudo detido das conjugações regulares.

8 - Estudo detido dos verbos regulares e suas diversas especies.

9 - Morphologia e taxionomia dos adverbios.

$10^{\circ}$ - Morphologia e taxionomia das preposições.

$11^{\circ}$ - Morphologia e taxionomia das conjuncções e interjeições.

$12^{0}$ - Processos de formação das palavras: composição e derivação.

$13^{0}$ - Syntase. Noções geraes de syntase. Estudo das preposições.

$14^{\circ}$ - Syntase do substantivo.

$15^{\circ}$ - Idem do adejectivo.

$16^{\circ}$ - Idem do pronome e do artigo.

$17^{\circ}$ - Idem do verbo. Emprego dos tempos e modos com especialidades dos infinitivos.

$18^{\circ}$ - Syntase do verbo. Emprego do infinito e dos participios.

19 - Syntase das palavras invariaveis. Da preposição.

20 - Syntase das palavras invariaveis. Do adverbio e da conjuncção.

210 - Gramatica historica: Alterações lexicas: archaismos, neologismos e idiotismos. Modificações sofridas pelo hespanhol nas Republicas Americanas.

$22^{\circ}$ - Elementos essenciaes de phonetica hespanhola. Suas relações com a portugueza.

23ํ- - Estudo morphologico do substantivo. Casos e flexões.

$24^{\circ}$ - Estudo morphologico do adjectivo. Casos e flexões.

$25^{\circ}$ - Estudo morphologico do artigo e do pronome.

260 - Estudo morphologico do verbo. Transformação da conjugação latina na conjugação hespanhola. Apparecimento dos verbos auxiliares.

$27^{\circ}$ - Estudo morphologico do adverbio e da conjuncção.

28ㅇ - Estudo morphologico da preposição.

29 - Noçoes geraes sobre a origem e formação da lingua hespanhola. Sua evolução.

$30^{\circ}$ - Relações historicas da lingua hespanhola com as demais linguas romanicas, especialmente com a portugueza.

$31^{\circ}$ - Principios geraes de Semantica hespanhola.

$32^{\circ}$ - Da syntase em geral e do estylo.

$33^{\circ}$ - Vista geral sobre o desenvolvimento das principaes phases da litteratura hespanhola. (BRASIL, 1919)

Este programa de ensino é relevante para o entendimento da institucionalização da língua espanhola como disciplina escolar, juntamente com a gramática composta pelo professor da disciplina, pois, os "conteúdos explícitos e baterias de exercícios constituem então o núcleo da disciplina". Porém, como tratava-se de uma disciplina facultativa, a falta de exames finais seria um ponto negativo nesse processo, pois, perdeu-se "[...]o peso considerável que as provas do exame final exercem por vezes sobre o desenrolar da classe e, portanto, sobre o desenvolvimento da disciplina [...]" (CHERVEL,1990, p. 205206).

A inclusão da disciplina no Colégio Pedro II foi comunicada aos colégios oficiais ou equiparados de ensino secundário pelo Ministro da Justiça. Sendo assim, foi mais um componente curricular do qual esses estabelecimentos passaram a buscar e implantar em seus currículos, nem sempre com êxito no preenchimento da vaga aberta, como no exemplo do Liceu de Goiás. O diretor do estabelecimento abriu concurso público, em abril de 1920, para o preenchimento da cadeira de italiano e espanhol, criada pelo regulamento expedido pelo Decreto ํㅜ 6.395, de 20 de dezembro de 1919, sem êxito. Em dezembro de 1920, a Congregação do Liceu foi obrigada a anular a inscrição aberta para a cadeira, por falta de candidatos recebendo, entretanto, pedido de nomeação para a disciplina de italiano, independente de concurso. A anulação foi feita após solicitação de orientações ao Conselho Superior do Ensino, que se manifestou favorável, visto que a matéria era 
facultativa, ou seja, oficialmente não era obrigatório que os estabelecimentos equiparados ao Colégio Pedro II ofertassem essa categoria de disciplinas.

Esse episódio demonstrava a dificuldade que os estabelecimentos tinham em contratar professores e seguir o mesmo currículo que o "Colégio-Modelo". Aliás, não há informações sobre outro Colégio, além do Pedro II, que tenha logrado êxito na aprovação e nomeação de professor catedrático de espanhol. A partir do conhecimento pelos diretores de estabelecimentos oficiais de que o Colégio Pedro II incluiu a cadeira de Espanhol no seu currículo, foram abertos novos concursos para a matéria em todo o país. No Quadro 1 constam as aberturas da cadeira de espanhol em alguns desses estabelecimentos:

Quadro 1 - Concursos para a cadeira de espanhol.

\begin{tabular}{|l|c|}
\hline \multicolumn{1}{|c|}{ Instituto Secundário } & Ano \\
\hline Liceu de Goiás & 1920 \\
\hline Liceu Cuiabano & 1921 \\
\hline Ginásio Amazonense & 1921 \\
\hline Liceu de Cuiabá & 1924 \\
\hline
\end{tabular}

Fonte: Jornais consultados.

Em Sergipe, sob o comando do General Manuel P. de Oliveira Valadão (18491921), Presidente do Estado, o colégio de Ensino Secundário Atheneu Sergipense conseguiu sua equiparação ao Colégio Pedro II, pela segunda vez, já que, como dito antes, a primeira vez foi em 1908:

A equiparação do Atheneu Sergipense ao Colégio de Pedro II, que vinha sendo tentada desde a promulgação da Lei Maximiliano, chegou, afinal, em fevereiro de 1918, seguida de inspeção permanente por ato do Ministro da Justiça de 23 do mês seguinte trazendo, como conseqüência, o aumento da matrícula daquele estabelecimento, atingindo já nesse ano 89 alunos contra 59 do ano anterior. (NUNES, 2008, p. 238)

Não só o aumento de alunos, outras consequências se seguiriam a essa equiparação, que muito esforço demandou do governo estadual: o Atheneu Sergipense teria que incorporar as alterações do regulamento do Colégio Pedro II promovidas pelo Governo Federal, no que se refere a currículo e livros adotados. Dessa forma, em 31 de março de 1921, pouco mais de três anos da equiparação, um novo regulamento foi implantado, aprovado pelo Decreto $n^{\circ} 721$ "[...] para acompanhar a estrutura do Colégio Pedro II [...]" (NUNES, 2008, p. 244). Possivelmente, além de outras ações a serem tomadas para estruturar o colégio sergipano, houve nesse momento a necessidade da criação da cadeira de espanhol, como forma de manter o mesmo currículo do Colégio Pedro II.

O ensino no Colégio Pedro II e congêneres, na década de 1920, tinha a finalidade de preparar o alunado para prestar o exame vestibular das instituições oficiais de ensino superior do país. O ensino das línguas vivas consistia basicamente em comunicação, 
leitura e tradução de obra literária, era um ensino eminentemente prático. Os Colégios deveriam aplicar provas escrita e oral. A avaliação escrita constava de tradução de obra literária, clássica e difícil, de preferência em verso e era permitido o uso de dicionário. Para o exame oral, o aluno deveria ser verificado em leitura e tradução sem auxilio de dicionário, bem como de palestra entre o aluno e o examinador (BRASIL, 1915). Contudo, o espanhol entrou nos currículos como disciplina facultativa, não sendo obrigatório seu conhecimento para prestar prova de vestibular. As línguas vivas obrigatórias nos vestibulares eram o francês e o inglês ou alemão. Este foi um dos motivos de haver pequena procura entre os alunos para o espanhol, o que culminou com a sua saída do currículo oficial em 1926.

O ensino da língua espanhola na educação secundária brasileira não teve longevidade, pois não havia interesse do alunado para cursar uma disciplina facultativa. Além de a disciplina não ser obrigatória nos vestibulares, a pseudo-facilidade em seu aprendizado afastou os alunos do estudo dessa língua românica.

O professor Nascentes, na Introdução de sua gramática, já ressaltava essa teórica facilidade de os brasileiros aprenderem a língua espanhola:

\begin{abstract}
O espanhol é parecidissimo com o portuguez, como toda a gente o sabe. Quem conhece o portuguez, com facilidade lê e comprehende o espanhol; sentirá, é verdade, algumas deficiencias. Além disso é uma lingua familiar a nós por causa da immigração espanhola em nosso paiz, das companhias dramaticas, de operetas e zarzuelas que annualmente nos visitam, das relações com as republicas vizinhas. (NASCENTES, 1920, p. IV)
\end{abstract}

É interessante notar que na sequência do seu texto, Nascentes (1920, p. IV) afirma que "a extrema semelhança das duas linguas, entretanto (parece até um paradoxo), é a maior difficuldade que encontramos, pois quando mal pensamos que uma palavra, uma locução, ou uma fórma, se encontra em ambas as linguas, defrontamos profunda differença". Tal como este demonstra que, como qualquer língua estrangeira, seria necessário um estudo sistemático e aprofundado para o conhecimento e a prática da língua espanhola.

\title{
Considerações finais
}

Apesar do "Americanismo" ter influenciado a implantação da língua espanhola no Ensino Secundário brasileiro, no início do século $X X$, o seu ensino não contemplava as aspirações dos alunos e da sociedade que o recusou, pois a prioridade naquele momento era a de investir esforços para as disciplinas que os conduzissem ao objetivo principal, que era o ingresso em instituições superiores de ensino. O Governo do Brasil introduziu o ensino da língua espanhola como mera gentileza ao ato do Governo do Uruguai, sem agregar ao seu ensino qualquer outro objetivo. $O$ foco não era propiciar ao estudante uma opção para acesso ao conhecimento científico ou a leitura de grandes vultos da literatura universal. A comunidade escolar recusou, naquele momento, a disciplina que, de certa forma, fora imposta pelo poder público, não se constituindo, então, em uma finalidade real. Prova disso é que a disciplina não tinha sequer exames finais, que, se utilizados poderiam chamar a atenção dos alunos e do mestre, o que poderia ter exercido grande influência no desenvolvimento das classes e, como ressaltado anteriormente, são um constitutivo da disciplina escolar. 


\section{Referências}

A ÉPOCA. Rio de Janeiro, DF, 31 de Out. de 1917, Ano VI, edição 1937. Disponível em: <http://memoria.bn.br>. Acesso em: 04 fev. 2013.

A PROVÍNCIA. Recife, 9 de Jan. de 1921, Ano 1, no 8, edição 1921. Disponível em: $<$ http://memoria.bn.br>. Acesso em: 06 jun. 2013.

ALVES, Eva Maria Siqueira. O Atheneu Sergipense: uma casa de educação literária examinada segundo os planos de estudos 1870-1908. 2005. $318 \mathrm{f}$. Tese (Doutorado em Educação) - Programa de Estudos Pós-Graduados em Educação, Pontifícia Universidade Católica de São Paulo, São Paulo, 2005.

BRASIL. Collecção das leis da Republica dos Estados Unidos do Brasil de 1905. Volume 1. Rio de Janeiro: Imprensa Nacional, 1907.

Congresso. Senado. Decreto 11.530 de 18 de março de 1915. Reorganiza o ensino secundario e o superior na República. Disponível em: <http://www6.senado.gov.br/legislacao/ListaTextolntegral.action?id=36895>. Acesso em: 21 jul. 2013.

Constituição da República dos Estados Unidos do Brasil de 1891. Disponível em: <http://www.planalto.gov.br/ccivil_03/Constituicao/Constitui\%C3\%A7ao91.htm>. Acesso em: 21 jul. 2013.

Ministério da Justiça e Negócios Interiores. Programas de ensino da cadeira de espanhol aprovado em 5 de abril de 1919. Diário Oficial da União. Rio de Janeiro, DF, 5 de jul. de 1919. Disponível em: <http://www.jusbrasil.com.br>. Acesso em: 04 fev. 2010.

. Ministério das Relações Exteriores. Relatório dos anos de 1917 a 1918 apresentado ao Presidente da República dos Estados Unidos do Brasil pelo Ministro de Estado das Relaçoes Exteriores comprehendendo o período decorrido de 1 de maio de 1917 a 3 de maio de 1918. Vol I. Rio de Janeiro: Imprensa Nacional, 1920. Disponível em: <http://brazil.crl.edu/bsd/bsd/hartness/index.html>. Acesso em: 04 fev. 2013.

. Relatório apresentado ao Presidente da República dos Estados Unidos do Brasil pelo Ministro de Estado das Relações Exteriores compreendendo o período decorrido de 1 de maio de 1917 a 1 de maio de 1918. Disponível em:

<http://brazil.crl.edu/bsd/bsd/u1788/000028.html>. Acesso em: 01 out. 2012.

CARVALHO, José Murilo de. A formação das almas: o imaginário da república no Brasil. 21를 reimpressão. São Paulo: Companhia das Letras, 2012.

Os bestializados: o Rio de Janeiro e a República que não foi. 3. edição. 15a reimpressão. São Paulo: Companhia das Letras, 2005.

CHAMON, Carla Simone. Escolas em reformas, saberes em trânsito: a trajetória de Maria Guilhermina Loureiro de Andrade (1869-1913). Coleção História da Educação. Belo Horizonte: Autêntica Editora, 2008.

CHERVEL, André. História das disciplinas escolares: reflexões sobre um campo de pesquisa. LOURO, Guaracira Lopes (Trad.). Teoria \& educação, Porto Alegre, 1990, n. 2. p. 177-229.

CORREIO DA MANHÃ. Rio de Janeiro, DF, 12 de fev. de 1916. Disponível em: $<$ http://memoria.bn.br>. Acesso em: 10 jun. 2013.

CUNHA, Luiz Antonio. A universidade temporã: o ensino superior da Colônia à Era de Vargas. Rio de Janeiro: Civilização Brasileira, 1980.

FAZOLI FILHO, Arnaldo. Fundação Escola Álvares Penteado 1902-1992: noventa anos 
servindo ao ensino comercial e econômico. São Paulo: Letras \& Letras, 1992.

FERRONATO, Cristiano de Jesus. Das aulas avulsas ao Lyceu Provincial:as primeiras configurações da instrução secundária na Província da Parayba do Norte(1836-

1884).João Pessoa:UFPB,2012. Tese do Programa de Pós-Graduação em Educação da UFPB.

FOLHA DE SERGIPE. Aracaju, SE, 3 de dez. de 1908. Disponível em: $<$ http://memoria.bn.br>. Acesso em: 31 dez. 2013.

GAZETA DE NOTÍCIAS. Rio de Janeiro, DF, 04 de set. de 1919. Disponível em: $<$ http://memoria.bn.br>. Acesso em: 10 jun. 2013.

. Rio de Janeiro, DF, 10 de set. de 1919. Disponível em: <http://memoria.bn.br>. Acesso em: 10 jun. 2013.

. Rio de Janeiro, DF, 28 de ago. de 1919. Disponível em: <http://memoria.bn.br>. Acesso em: 10 jun. 2013.

HOBSBAWM, Eric. Era dos extremos: o breve século XX 1914-1991. Trad. Marcos Santarrita. 2. edição. 48a reimpressão. São Paulo: Companhia das Letras, 2012.

NASCENTES, Antenor. Discurso proferido em 23 de setembro de 1952 no salão nobre do externato do Colégio Pedro II por ocasião do recebimento do título de professor emérito. Rio de Janeiro: Jornal do Commercio, 1952.

O PAIZ. Rio de Janeiro, DF, 15 de maio de 1919. Disponível em: <http://memoria.bn.br>. Acesso em: 12 fev. 2013.

PRADO, Eduardo. A illusão americana: com um prefacio e estudo biographico do autor pelo Dr. Leopoldo de Freitas. 4aㅡ edição revista. São Paulo: Livraria e Officinas Magalhaes, 1917.

SOUZA, Josefa Eliana. O programa de instrução pública de Tavares Bastos (1861-1873): concepções a partir do modelo norte-americano. São Cristóvão: Editora UFS, 2012.

VASCONCELOS, Maria Celi Chaves. A casa e os seus mestres: a educação doméstica como uma prática das elites no Brasil de Oitocentos. 2004. 336 f. Tese (Doutorado em Educação) - Departamento de Educação, Pontifícia Universidade Católica do Rio de Janeiro, Rio de Janeiro, 2004.

VECHIA, Ariclê. Imperial Colégio de Pedro II no século XIX: portal dos estudos históricos franceses no Brasil. In: VECHIA, Ariclê \& CAVAZOTTI, Maria Auxiliadora (Orgs.). A escola secundária: modelos e planos (Brasil, séculos XIX e XX). São Paulo: Annablume, 2003.

VECHIA, Ariclê; LORENZ, Karl Michael (Orgs.). Programa de ensino da escola secundária brasileira: 1850-1951. Curitiba: Ed. do Autor, 1998.

VIEIRA, David Gueiros. O protestantismo, a maçonaria e a questão religiosa no Brasil. Brasília: Editora da Universidade de Brasília, 1980.

WOGAN, Daniel S. A literatura hispano-americana no Brasil: 1877-1944. Bibliografia de crítica, história literária e traduções. Baton Rouge: Lousiana State University Press, 1948.

ANSELMO GUIMARÃES é Mestre em Educação e doutorando em Educação pela Universidade Federal de Sergipe. Publicou História do Ensino de Espanhol no Brasil (2011) e La Institucionalización de la Enseñanza de las Literaturas Española e Hispano-americanas en Brasil (1870-1942) (2014). 
Endereço: Rua Érico Alves dos Santos, n. 59, conjunto Santa Lúcia - bairro Jabotiana 49095-550 - Aracaju/Sergipe - Brasil.

E-mail: anselmo.guima@gmail.com

JOSEFA ELIANA SOUZA é professora adjunta na Universidade Federal de Sergipe, Doutora em Educação pela Pontifícia Universidade Católica de São Paulo. Publicou: O programa de instrução pública de Tavares Bastos (1861-1873): concepções a partir do modelo norteamericano (2012) e História e Memória: Universidade Federal de Sergipe (1968-2012) (2015).

Endereço: Rua Lourival Chagas, 125, Edifício Harmonie Jardins Rèsidence, 50 - bairro Grageru - 49025-390 - Aracaju/Sergipe - Brasil

E-mail: elianasergipe@uol.com.br

Recebido em 30 de maio de 2015.

Aceito em 14 de outubro de 2015. 